\title{
A time to look within curricula-Nursing students' perception on sexuality and gender issues
}

\author{
Maryann Washington ${ }^{1}$, Edwina Pereira ${ }^{2}$ \\ ${ }^{1}$ St. John's College of Nursing, St. John’s National Academy of Health Sciences, Bangalore, India \\ ${ }^{2}$ International Services Association, Bangalore, India \\ Email:maryannvc@gmail.com, dwinapereira@gmail.com
}

Received 10 November 2011; revised 1 December 2011; accepted 18 January 2012

\begin{abstract}
Nursing students could be viewed as dynamic change agents given the knowledge and skills they would be equipped with. Amongst all areas to be addressed in their clientele of the hospital or community setting, one key area that a nurse could focus on is sexuality. This however is often neglected for simple reasons such as lack of knowledge, embarrassment, fear of intrusion on privacy, or it is perceived as an un-important concern of the patient. Focus groups discussions combined with self report were conducted on 84 nursing students selected by the faculty from three institutions of nursing to assess their perceptions related to sexuality and gender issues, and thus extrapolate on their learning needs within the curriculum. Student expressed discomfort in caring for patients who had sexual expressions and relationships different from the accepted cultural norm; perceived sexuality primarily as heterosexual relationship; helplessness when faced with sexual harassment in the health care field and gaps in their present curricula in relation to contextualization of sexuality and gender issues.
\end{abstract}

Keywords: Nursing Students; Sexuality; Gender; Sexual Harassment; Perceptions; Focus Group Discussions

\section{INTRODUCTION}

Historically, the study of nurses' attitudes toward sexuality has been both sporadic and sparse in the developed countries, and practically absent in the developing countries. Studies conducted in developed countries have been based on two lines of inquiry [1]. Firstly, on those that often culminated in the classification of nurses as liberal or conservative in their views about specific sexrelated behaviors. Secondly, on those that had the potential for identifying concepts and relationships which described and explained nurse-patient interactions in so- cially sensitive situations.

Sexuality has been recognized internationally as an aspect of human health. Although it has been reported that patients had found it appropriate to discuss their sexual concerns with nurses [2-4], this was rarely included in their interactions with their patients. Several perceived barriers during health care professional-patient interactions have been reported such as lack of knowledge and difficulty with the concept of including sexuality within holistic care [5]; boundary issues with fears of causing offense, seeming intrusive or inappropriate; personal discomfort, anxiety and inappropriate skills to address such issues especially with its multitude of variations; and time/privacy constraints [6].

Studies on nurses' knowledge and attitudes about their own and their patients' sexuality have reinforced [7], that even nurses need more education about human sexuality. As early as 1975, the WHO [8] recognized the need for education and training of health professionals on human sexuality in India. The knowledge, awareness and accepting attitudes essential to understanding the totality of sexuality are integral to holistic nursing care.

As part of this holistic care, nurses and other health care providers are often required to help people [2-7] overcome problems related to sexual matters. They may be faced with questions about family planning, fertility regulation methods and pregnancy and concerns about sexual functioning. Nurses could thus be viewed to be in a prime position to address issues regarding sexuality with their patients. Thus acceptance of the basic elements of sexual health as recommended by the World Health Organization [8] could possibly replace health care professional's microscopic view that sexuality primarily centers on procreation/reproduction/negative consequences (infection) with a positive approach to it, for the enhancement of life, personal relationships, and health care maintenance. To the extent people with sexual problems look at health professionals for guidance and advice; it is imperative punitive or negative attitudes, use of careless statements or inappropriate methods to discuss such is- 
sues are avoided [9] as these are likely to cause serious damage to their sense of value to health maintenance.

\section{REVIEW OF LITERATURE}

A growing body of knowledge indicates that problems in human sexuality are more pervasive and more important to the well being and health of individuals in many cultures. There are important relationships between sexual ignorance, misconceptions and diverse problems of health and the quality of life [8]. More important is the idea that sexuality is so intimately tied up with gender that it may be sometimes difficult to see where one ends and the other begins. Traditional notions about women's sexuality make it virtually synonymous with her reproductive function and motherhood. It has and is still seen as the natural expression of female sexuality. Society at large might be one sided when sexuality is addressed, with focus on violence and diseases associated with sexual behaviors or for its procreative function. Society and legal decisions reveal how deeply entrenched is the idea that normal sexuality must be organized around heterosexuality, thus implying peno-vaginal intercourse. Rarely is the idea perceived or recognized that heterosexuality is a power relationship of men over women.

Without doubt, cognizance of a universally acceptable definition of human sexuality is hard; however a critical view of the definition of sexual health could facilitate an acceptable definition of it. According to the WHO [8], sexual health is the integration of the somatic, emotional, intellectual and social aspects of sexual being, in ways that are positively enriching and that enhance personality, communication and love. Sexual health and thus human sexuality which is buried therein has thus been described to include three basic elements [10] such as the

- Capacity to enjoy and control sexual and reproductive behavior in accordance with a social and personal ethic

- Freedom from fear, shame, guilt, false beliefs and other psychological factors inhibiting sexual response and impairing sexual relationships

- Freedom from organic disorders, diseases and deficiencies that interfere with sexual and reproductive functions.

Acceptance of these basic elements of sexual health reinforce the need for a positive approach to human sexuality; not merely the counseling and care related to procreation and or sexually transmitted infections. Fundamental to this concept are thus the right to sexual information and the right to pleasure. For this it is essential that healthcare professionals are trained during their formative years on this positive approach. However till date, health care professional's curricula especially that of nurses who are seen to be in a prime position to ad- dress these issues are centered on increased cognition of the reproductive function or problems related to it [11-13] rather than on skills they might require to deal effectively with such topics in the real world.

Typically nursing students are exposed to the real world of the hospital or community, right in the beginning of their training program. Nurses would thus need to be equipped with appropriate attitudes and skills to tackle such issues both in their professional and personal lives. There are several reasons why one would need to reconsider the approach to teaching such sensitive issues that seem to be a prevailing norm in the country. Firstly, the need for nurses to actually address these issues amongst the multitude of patients they might be providing care. Secondly the fact that they will need to face the growing complex challenges HIV infection brings with it. Thirdly the chances of occupational hazards they might face early in their training, typically the unacknowledged sexual harassment within the health care setting [14,15]. And lastly, their presumed incapacity to deal with these complex issues brought to the forefront by their clientele in the first year of their professional program. Approaches that are reported to improve the comfort levels of nurses include using educational films and written materials, conducting role plays to explore typical patient questions, and initiating conversation about sexuality with patients [5].

Attitudes and behaviors surrounding sexuality and gender carry profound meanings for women and men in society and affect the quality of life $[9,16]$ in fundamental ways. Sexual attitudes and behaviors of individuals could influence contraceptive adoption, choice and the effective use of their choice. More generally one must be cognizant that sexual relationships often incorporate power disparities based on age, class, race and patronage as well as gender. Approaches recommended by patients for increasing their comfort level to discuss these issues with health care provider include adopting an open and nonjudgmental listening mode, distinguishing between the physical and emotional aspects of sexual issues, and promoting peer counseling [5].

The objectives of this paper is to describe perceptions of nursing students with regards to sexuality, gender and the challenges faced thereof; and thus to extrapolate their learning needs that may need to be revisited within their curricula. This paper is an outcome of the process used to adapt and develop a module to train nursing students in sexuality and gender contextually [17].

\section{METHODS}

Four institutions were selected through purposive sampling techniques within Bangalore city in India. The criteria included administrative approval for conducting the 
project titled “Training Modules on Sexuality and Gender for Nursing Students" for a two year period; representation of the different types of institutions (Table 1) based on how they were managed such as "private" if privately funded (coded as A), "government supported" (coded as B and C) or administered by a "private religious minority/trust” (coded as D). Institution A and D provided both the diploma (referred to GNM program) and the degree (referred to the BSc program) nursing program; institution B only the BSc program; and institution $\mathrm{C}$, only the GNM nursing program.

Since sexuality was presumed to be a closed topic, not so easily discussed, focus group discussion (FGD) method was used as a means to collect information. In all 11 FGDs (Table 1) were conducted in institutions A, B and $\mathrm{C}$. The faculty members of the institution were briefed about the purpose of the FGDs and asked to select between 6 - 10 members from each class of the GNM and or BSc program, to ensure representation of level and gender of students.

The students $(n=84)$ age ranged from 18 - 30 years (Mean $20.34 \pm 2.32$ years). Most of the participants 60 (71.4\%) were female students. All participants 84 (100\%) mentioned that they heard the word "sexuality", "sex" while $3(3.6 \%)$ mentioned that they had not heard the word "gender". Only 39 (46.4\%) had training or classes on sexuality and gender in the past. The past referred to either before or after joining the nursing profession. Most of the participants 61 (72.6\%) reported that they had discussed or read about sexuality and gender.

The tools consisted of the FGD guide, survey performa, and digital recorder. The FGD guide was validated and pilot tested for feasibility. The survey performa helped to ascertain baseline information such as age, sex, academic year, and program. It also included additional information such as awareness of the words sexuality, gender and sex, and source of information on these topics. In addition there was a nine statement 5-point Likert scale ranging from "extremely uncomfortable" to "extremely comfortable” to ascertain student's perception of their comfort levels to deal with different clientele. The consent form contained specific information as to the purpose of the FGDs, how the personal information would be kept confidential and the way the information

Table 1. Number of FGDs per institution.

\begin{tabular}{cccc}
\hline Institution & $\begin{array}{c}\text { No. of } \\
\text { FGDs }\end{array}$ & $\begin{array}{c}\text { No. of } \\
\text { students }\end{array}$ & $\begin{array}{c}\text { \% selected from } \\
\text { the institution }\end{array}$ \\
\hline B $(\mathrm{n}=200)$ & 3 & 24 & $12 \%$ \\
A $(\mathrm{n}=493)$ & 4 & 32 & $\mathbf{6 . 5 \%}$ \\
C $(\mathrm{n}=256)$ & 4 & $\mathbf{2 8}$ & $\mathbf{1 0 . 9 \%}$ \\
TOTAL $(\mathrm{n}=949)$ & $\mathbf{1 1}$ & $\mathbf{8 4}$ & $\mathbf{8 . 8 5 \%}$ \\
\hline
\end{tabular}

would be used. The digital recorder was used to record the proceedings of the FGDs.

Student participants were assembled in a class room provided by the institution. They were briefed about the purpose of the project and the FGD, and were asked to sign the consent form. Then the survey sheet was completed, following which the FGDs were conducted. All but 2 (18.8\%) of the FGDs were recorded using the digital recorder, as participants expressed desire for not recording the proceedings but permitted for verbatim documentation of the session. Each FGD took approximately 2 hours. An assistant helped in taking down interactions. The FGDs were later transcribed using the recorded version. Random quality check was made of transcripts by an independent source.

\section{RESULTS}

The findings are presented based on the objectives of the paper.

\subsection{Determine the Perceptions of Nursing Students with Regards to Sexuality}

1) Perception on comfort levels to look after patients with varied sexual expressions

Students expressed more discomfort (extremely uncomfortable and uncomfortable combined) to deal with patients who had different sexual expressions and relationships. More than half the proportion of students responded that they would feel uncomfortable (Figure 1(b)) if they looked after a person who

- had sexual relationship with the same sex (69.1\%Figure 1(b));

- had sexual relationships with both sexes (62.1\%Figure 1(c));

- if married and had sexual relationships with the same sex (59.5\%-Figure 1(f));

- if married but had sexual relationships with the multiple partners (58.1\%-Figure 1(a));

The proportion of students who expressed discomfort (extremely uncomfortable and uncomfortable) based on their response to the survey was lesser if they had to look after a patient with HIV (41.7\%-Figure 1(d))) and Hepatitis B (39.3\%-Figure 1(e)).

Below is highlighted the perception of students with regards to sexuality and gender issues. The responses quoted reflect only those of the students included in the FGD. The fact that the faculty members of the institution were briefed about the purpose of the study, could have influenced possibly the selection of the students. However since these were responses of students from different institutions it could be assumed that it would possibly reflect that of the general population of student body.

2) Perception towards sexuality 


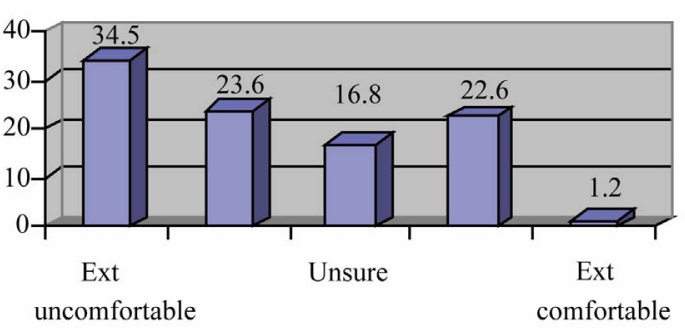

(a)

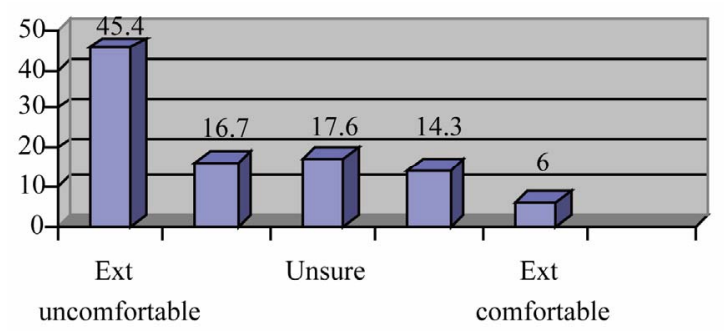

(c)

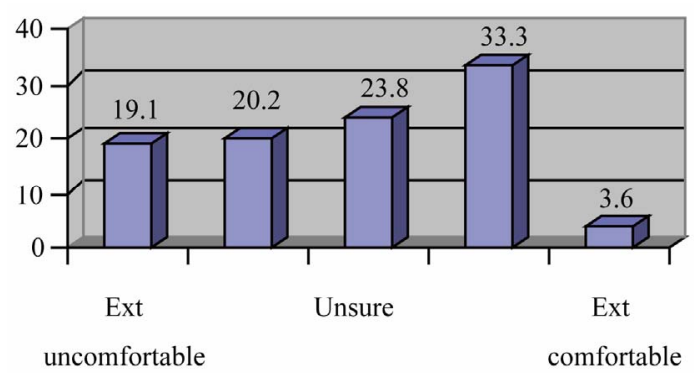

(e)

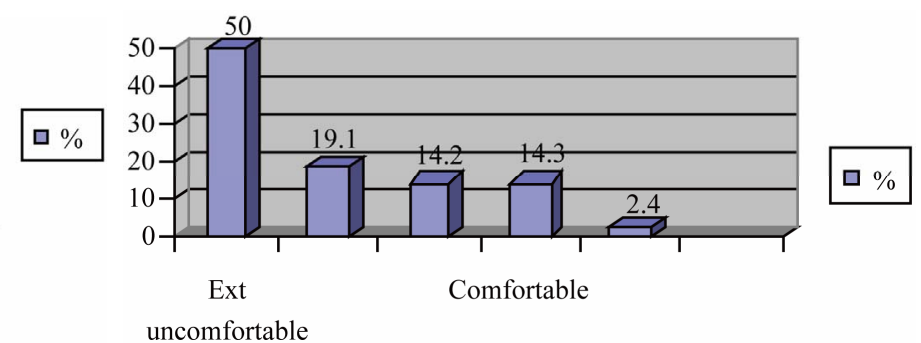

(b)

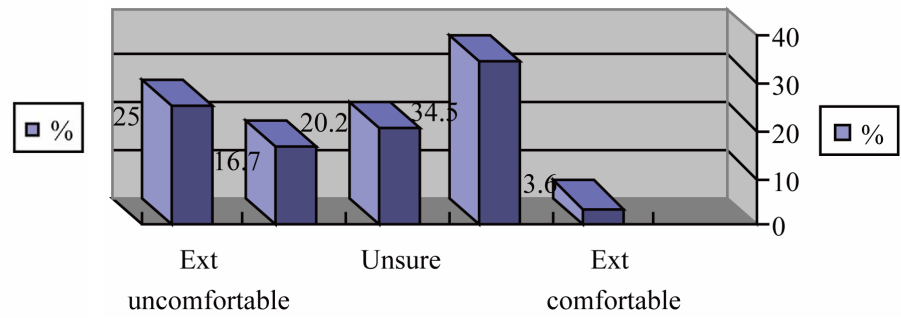

(d)
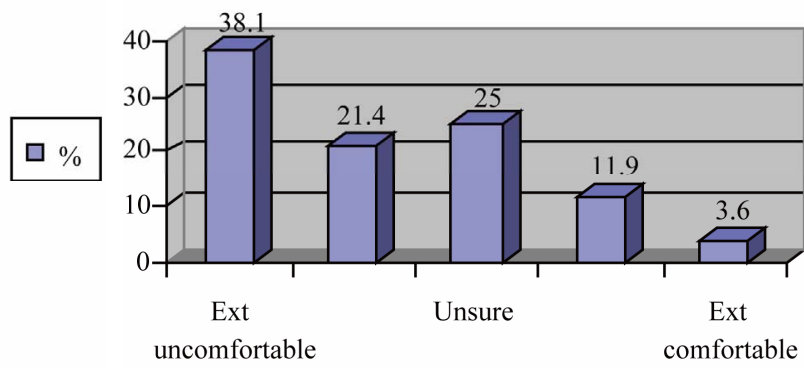

(f)

Figure 1. (a) How would you feel if you were to look after a patient who has more than one sexual partner even when married? (b) How would you feel if you were to look after a patient who has sexual relationship with same sex? (c) How would you feel if you were to look after a patient who has sexual relationship with both the sexes? (d) How would you feel if you were to look after a patient who has HIV infection? (e) How would you feel if you were to look after a patient who has Hepatitis B? (f) How would you feel if you were to look after a patient who is married and has sexual relationships with the same sex person also?

Students' perceptions (see quotes of student's responses given below as per institution code) towards sexuality tended to be fixed on just penetrative sex and dominantly on heterosexual relationships as the most "pure" "culturally" accepted mode of sexual expressions, with a prime function of procreation. Although a few did mention that sexuality is more than just sex, they tended to conclude it revolved around heterosexual relationships.

- "It may be a human relationship. It may be the reason for satisfaction and gratification. It may be the sexual act also. In an individual it may be normal” (A)

- "Attraction towards opposite sex" (A)

- "It is intercourse (sexual intercourse)" (C)

- "No (it is not intercourse), it is a relationship between a man and woman where they can understand each other" (C)

- "Sex is the part of sexuality. It is not only intercourse. It is our mind, the thinking, a feeling between humans.
It could be attraction between men and women” (C)

- "It's a normal process in nature. Its not a sin or something. Its a natural process. Its a process by which the husband and wife bring out the new generation to the world" (C)

- "Physical and psychological changes are gender. Sex is a relationship" $(\mathrm{C})$

- "To me it is something that is sacred and something that is a part of every person...it is meant for procreation, making the next generation” (B)

- "It is something more than just relating to sex...it is how I think of myself, how I would show myself as a woman, I would behave socially...it is more internal how I see myself” (B)

3) Perception on Sexual Needs

Although sexual needs were perceived as similar for boys/men and girls/women, they tended to be expressed differently primarily due to social/cultural restrictions or controls (see quotes of student's responses given below 
as per institution code).

- "The boys will express their sexual feeling but girls won't express it. They feel shy to express it. They control it when they need it" (A)

- "Boys think of their enjoyment and they will have it for short periods, but girls take long time to express their needs. It depends on each individual” (A)

- "No women will express her sexual need. If she expresses also there would be a bad name for her. It is not wrong actually but the society will blame her" (C)

- "Sexual needs are different. Sex is a pleasure for the men as they have a lot of stamina and they cannot control the sex. But the women she can control if she is not willing to have it, often when she cannot control the man she will undergo it” (A)

- "The women should have self control and avoid..." (C)

- "Even if it is a boy or girl they must have control in sex before marriage” (C)

- "It differs. The boys go around for sex but the girls won't go. The boys need it so they go out and get it” (C)

- "Men are dominant. Women are blamed if she exposes her sexual need. Till marriage they must be in control. After marriage only they must have sex" (C)

- "The boys always do not hesitate to express their sexual needs, but even if a girl wants to she will think of society and what they will think of her" (B)

- "In society it is considered wrong because it has come from the ancient time. Women are not supposed to expose her sexual feeling. It's a tradition. In tradition if man does it (shows his sexual need) it's ok but if a female does, it's wrong” (B)

4) Perception on Sexual Health

Sexual health was perceived more in the context of prevention of disease/infections (see quotes of student's responses given below as per institution code). Their concept of sexual expression seemed to be governed by societal or cultural or religious restraints especially imposed on girls/women than equally on both the sexes

- "Having sex in good manner and should not have sexual relationship with same sex" (C)

- "Some people even if counseled about multiple sex they won't listen. For them they must use condoms and can be safe" (C)

- "To have sex in a healthy way. To use condoms, if one is having sex before marriage. If the girl is very weak and she cannot control the boy then they must use condoms for keeping the girls in safer side and then there are no further complications" (C)

- "Having sex only with one partner either it may be boy or girl, one must have sex with only one” (B)

- "Sexual health is where there is a mature relationship between a boy and a girl” (B)
5) Perception on Sexual Rights

Discussion on sexual rights revealed that they perceived relationships (see quotes of student's responses given below as per institution code) to be mainly between male and female, violations within this relationship or within the sanctity of marriage.

- "But in some cases, the girl is forced, and the boys are more in control, we are in a male dominated country, and so there is problem and the girls are the ones who will have to face the consequences, nobody will ask the boy ... but the girl is always blamed” (B)

- "It depends on the culture ... nowadays in educated families there is no difference how they treat men and women....young men and women” (B)

- "Once, I read in newspaper about a couple who had married. In that particular night the husband was interested in sex but the wife was not interested. So he forced her and was happy. But the wife also has as right to oppose this. This is a form of abuse" (C)

- "Sexual right is that whether he/she wants to have (sex) or not. It must not be force full” (B)

- "When a child is raped by own family members" (B)

- "In the park a girl was raped by a man who was very old man. She was 12 years old girl” (A)

6) Perception on Homosexuality

Perceptions about looking after a patient who disclosed homosexual status was skewed towards it being wrong, a typical male behavior, or that it could be changed with counseling and therapy (see quotes of student's responses given below as per institution code).

- "If the patient is homosexual then we will try to educate him and bring him out of the thoughts that he has" (A)

- "We behave very professionally with them. We must not be too close to them. We must change the attitude. We must not hesitate to treat them. In many countries it is happening but in our country I think it not happening more. So if we educate them definitely we can control his homosexual behavior" (A)

- "We should take care of that patient and adjust to the patient and make them understand its bad" (C)

- "If the nurse had the capacity to change the patient mind and she can treat them" (B)

- "If we go generally we won't feel so uncomfortable to deal with such patients. But we will be in shock to listen that the patient has sex with same sex. Generally it is not expected, but we will provide care” (B)

\subsection{Identify Perceptions of Nursing Students with Regards to Sexual Harassment}

1) Perception of Vulnerability to Sexual Harassment

Most nursing students acknowledged the vulnerability of nurses towards sexual harassment (see quotes of student's responses given below as per institution code). 
According to the Supreme Court of India, sexual harassment is not just personal injury to the affected woman but a violation of her rights to equality in the workplace [14].

- "When we are posted in the community they comment on us (nurses) and we will are afraid of these street side guys who will be sitting around" (A)

- "One of my friends she was in the clinic and there was a patient who was very weak and moody. So she was talking with him and was friendly with him. After he was better this man started following her” (A)

- "Yes they do (chance of molestation of nursing students). But in our society the senior doctors, because they have studied medicine they are very proud, feel they can do anything even misbehave with nurses. Sometimes outsiders also try to touch us" (A)

They perceived the risk for sexual harassment could be from any quarter such as patients or their caretakers/relatives/friends, the doctors and even ward attendants; based on the timing of duty, the place where they may be performing their duties, the type of procedure they were performing on the patient. Sexual harassment was perceived as verbal, physical or even emotional. Some of them preferred not to mention the word sexual harassment. They used words such as "difficulties", "misbehave", "such situations" or just narrated the incident that took place

- "When the nurse is pretty, the young boys want the same nurse to treat them" (C)

- "During night duties when the nurses treat the patients, the patients mind will go wrong and they try to misbehave with us. But we won't give a chance. If we have the knowledge of that (how to recognize a person who may sexually molest us) we can avoid such incidents" (C)

- "We face risk of all age patients. It is not only the patients but the ward boys too" (C)

- "While giving bed bath or during catheterization" (B)

- "The doctors during night duties..... they also trouble us" (B)

- "We are at risk in the hospital since we are looking after the patients. For us we may be doing our job but some may take it differently" (B)

- "Yes there are chances for us to be sexually harassed or molested...we are sometime alone in the wards...doing night duty...it could happen... in the psychiatry wards also" (B)

- "We are nurses. Definitely they will order .... give this give that! The ward boy also orders us and the well educated people think that we are there for doing their work and they will make us to do it" (C)

- "If the patients are admitted in hospital they use some bad words. Not only the patients but also the doctors, ward boys most of them misbehave with the nurses.
In this hospital itself the doctor was misbehaving with patients and nurses" (B)

- "Some people who come to hospital and they do not know how to behave with nurse or how to talk with nurse. So it is some type of harassment they do (A)

- "I will tell you an example. He (patient) was in ortho (orthopedic) section and he was operated in the spinal cord. He could not get up and when we (myself and one of my colleagues) went to give him a bed bath he would catch the hand here and there. We find it very difficult to treat such patients. We try to avoid but can't because he is a patient who even cannot get up” (C)

- "Yes as we are in nursing profession we might have that type of difficulties.... in harassing .....verbally or touching us where we don't want to be touched” (A)

2) Perceptions on Approach to Sexual Harassment

Sexual harassment was perceived to place them in typically helplessness situations (see quotes of student's responses given below as per institution code). The word helpless is used to describe their response to sexual harassment as it seemed like it would preferably not be reported, but tolerated due to their student status and for fear of their own self respect or that their behavior was suspect. "If we have close friends we would tell to them (about sexual harassment) but we cannot speak to any other person because they make it a big issue and it may affect our future also (A)

- "If we complain to administrator they have to face other type of problems” (S)

- "Rarely will we report to authority....any way we are students and we think we should not tell it to any one" (B)

- "If there is sexual harassment in girls, no women will come forward and boldly tell. They just keep quiet thinking that if I do publicity it will be a problem to my future. She will be at risk. Thinking of society she won't come out of the problem which she is facing, She won't approach anybody” (B)

\subsection{Enumerate Areas of Concern for Nursing Students That May Need to Be Addressed within the Curricula}

Gaps in the knowledge levels, to address issues of gender or even sexuality with their patients was perceived (Table 2).

Topics that were highlighted as important for the nursing curricula as perceived by the nursing students (see quotes of student's responses given below as per institution code)

- "We need to know more about sexuality and the sexually transmitted diseases and how to control it and prevent” (A) 
Table 2. Perception of nursing students with regards to curricula needs.

\begin{tabular}{lc}
\hline \multicolumn{1}{c}{ Item } & $\begin{array}{c}\text { Affirmative } \\
\text { response }\end{array}$ \\
\hline $\begin{array}{l}\text { Know enough about sexuality and gender to be } \\
\text { able to educate patients? }\end{array}$ & $42.8 \%$ \\
$\begin{array}{l}\text { Will be able to counsel patients with problems } \\
\text { related to sexuality and gender? }\end{array}$ & $45.2 \%$ \\
$\begin{array}{l}\text { Is important to add a component on sexuality in } \\
\text { the nursing curricula? }\end{array}$ & $97.6 \%$ \\
$\begin{array}{l}\text { Is important to add a component on gender/ } \\
\text { women's rights in the nursing curricula? }\end{array}$ & $95.2 \%$ \\
$\begin{array}{l}\text { Know enough about how sexually transmitted } \\
\text { infections happen? }\end{array}$ & $98.8 \%$ \\
$\begin{array}{l}\text { Know enough about contraceptive methods and } \\
\text { how they work? }\end{array}$ & $96.4 \%$ \\
$\begin{array}{l}\text { Know enough about pregnancy and pregnancy } \\
\text { related care? }\end{array}$ & $95.2 \%$ \\
\hline
\end{tabular}

- “About homosexuality we don’t know, so we want to know more" (A)

- "We need information on how to ask and how to collect the information from the patient”(C)

- "Normal sex behaviors" (B)

- "How to control the sex feeling in young age" (B)

- "How to control emotions, to face problems, to make decision in stressful situations (sexual harassment)" (B)

- "We also need information on self awareness, how to be in control ... how to manage these problems we face" (B)

Skills that were highlighted as important for inclusion in the nursing curricula as perceived by the nursing students (see quotes of student's responses given below as per institution code)

- "How to deal with such patients (those with STIs) or how to manage such situations and how to handle it?" (A)

- "How to tackle the problem if the patients are arrogant?” (A)

- "How to communicate to persons with sexually transmitted infections?” (A)

- "Yes we need more information how to escape from such situations (sexual harassment)" (A)

- "I am working in gynecology section. Once a woman came and asked me "can I have sex even though she has just delivered a baby that too only two days old baby?" I didn't know what to tell her. I know she should not have (sex) but I want to tell her the reason. To deal with such cases we need more information on sexuality and gender" (C)

- "Dealing with young patients. How to communicate with them. There is lots of difference in taking care of a seventy year and twenty year old young man. So we have to know how to deal with these two patients" (C)

- "I also think if we learn to communicate with people then most of our problems could be solved ... plus we also need to learn how to say no!! ... How to be able to recognize when a person could give us trouble" (B)

- "What I feel is we also need to know how to learn counseling ... yes we do learn about communicating ... What exactly to tell people with these problems... how to approach them we need that” (B)

- "How to control the emotions" (B)

- "To be able to show that if we do not like something" (B)

Methods suggested by nursing students that could be used when teaching sexuality and gender included the following (see quotes of student's responses given below as per institution code).

- "We could have it like this ... discussion in small groups" (B)

- "Case studies ... videos, or even lecture” (C)

- "We could also teach the public about these problems and how to prevent it" (C)

- "Videos or CD" (B)

\section{DISCUSSION}

There are several reasons why sexuality and gender issues need to be addressed and contextualized in the nursing curricula, rather than be fixated on the disease or medical model. Firstly issues concerning sex and sexuality are often interpreted as problems, or negatively and even today are considered "closed door" topics.

Secondly students who enroll for nursing program are mostly between 17 - 19 years, the late adolescent period or early adulthood period. Nursing programs are modeled differently from other health care professional programs, by the fact that from the first academic year students have direct contacts with patients or people in the community. They are expected to practice and gain skills in performing the basic nursing procedures. These include history collection, plan and implementation of care. Care could refer to either provision of required assistance to or performance of all activities of daily living (feeding, hygiene, elimination, or mobility needs etc). Some of these procedures performed could place the student nurse in vulnerably close proximity to the patient. They thus need skills and positive attitudes to ward off any advances or behaviors directed to them personally in such situations.

Thirdly nursing has been described as a caring profession. Health teaching and education is listed as one of the components of caring. Communicating about sexual matters require a certain amount of maturity and knowledge, healthy attitudes towards sexuality, and skills to 
handle them. If nurses are to develop these, they would require teachers who are adequately prepared to guide and train them in this field.

Fourthly most $(>80 \%)$ nursing students reside in the hostel. They come from different backgrounds. Presumably they are vulnerable to psychological problems by the very nature of their upbringing and the program. Given the changes in society, children are often protected in the family environment and decision making is farfetched. These, are expected in a span of four to six months when first exposed to the clinical environment of the hospital or the community, to demonstrate independent decision making with regards to challenges they are likely to face in their professional encounters. It is important to be aware and identify problems of students [19] it becomes even more pressing in nursing, the caring profession to be helped in maintaining their self esteem and to facilitate in self adjustment. One definite unspoken problem remains sexual harassment $[14,15]$ in the health care setting which these young individuals might encounter early in their training period unlike any of their peers. It is important that they are provided with skills to handle such issues without it backfiring on their self esteem.

Fifthly reports have suggested that prerequisites for a health care professional to teach, and counsel individuals on sexual functioning include knowledge, skill and comfort in discussing and working on these issues. Nursing thus stands out as a profession with the legitimate theoretical base [20]. It has been reported that self assured nurses, comfortable with their own sexuality could be more sensitive to the cues from patients that might indicate an area of sexual concern or dysfunction than those who are not comfortable with their own sexuality [21]. Thus as suggested by the students itself, training them early on these issues using different participatory and introspective methods $[5,18]$ as well as equipping them with life skills could be the key to effective functioning in the area of human sexuality. Those who are unsure of how to handle [22,23] such issues effectively in the field could learn to refer these to other more experienced health care professionals including the doctors.

Sixthly, from the FGDs with students it is evident that they have perceived existing gaps in the present curricula. Students did perceive (see quotes of student's responses in italics as per institution code) that they would be and are faced with many questions and doubts from patients on issues relating to sexuality that they either are not comfortable or they just lack the needed information to address. "Yes we need information because we have to deal with all types of patients. So if they ask any doubts on this part we have to explain to them. If we have knowledge only we can teach them" $(C)$. Typically students did feel that the topic must be dealt with in the first year itself, since that is the first time the student is exposed to the patient and the student is vulnerable to sexual harassment in any form as quoted by one nurse "the first year students, must learn how to deal with patients" $(C)$. The students also felt it would be advantageous to include topics that were contextual in a unit that would address sexuality and gender as a whole, "We would be able to protect ourselves, we can understand all the difficulties, we can educate the people and personally also it would help us more" (C); "How to make decisions in such situations (sexual harassment)" (B).

All groups after the FGD asked "what is sexuality? What is gender?" It is not so much the theoretical construction of the words, but the implications these words would have in their professional practice or on their personal experiences. Practicing nurses are reported to be more comfortable in discussing these issues with female patients and teenagers that with those of different sexual orientations and when they were trained to address these issues $[16,18]$.

\section{RECOMMENDATIONS}

It is evident that there are gaps within the present undergraduate nursing curricula in India [11,12] when it comes to contextualizing gender and sexuality. Students have a unit on professional adjustments, but even that does not address the possible challenges the students are likely to face when in contact with patients.

It would be good if students are given an overview of the topics on sexuality, sex and gender with the aim of making them aware of how gender could impact on sexual health. This could also make them aware of their own vulnerability to issues related to sexuality both in their personal and professional lives. Students need to be taught life skills right from the beginning of their course so that they would be aware of their rights within the workplace, able to face challenges and handle sexual harassment if it arises, with their self esteem and respect intact. Topics that could likely be covered through a unit on sexuality and gender for the first year nursing students of GNM or BSC programs include:

- Concepts of gender, sex and sexuality

o Why gender and sexuality for nurses

o Defining concepts of sexuality and gender

- Sexual and reproductive health and rights with no repetition of content that already exists in the curricula. This could also include relationship between gender and health; sexual violence

- Life skills

- Counseling skills

\section{CONCLUSIONS}

This paper has explored student nurses perceptions on 
sexuality and gender as well as on their experiences of sexual harassment during the clinical exposure in the hospital or the community. It has thrown light on some of the pressing issues of nursing students that often are misconstrued as irrelevant or of no importance. However these students are the future of the "caring profession". If steps are not taken to nurture in them a caring attitude, it is unlikely that the true spirit of nursing would evolve in these budding nurses.

It also highlights that sexual harassment in the workplace of students nurses is a reality but not acknowledged enough either by the authorities nor reported appropriately by students for several reasons. There appears to be obvious lacunae in the acknowledgement and relevance of training on life skills that is presumed to be of benefit to the student. One could extrapolate on potential gaps that exist in the nursing curricula with regards to gender and sexuality sensitization. Subsequent to this, a training module [17] was developed, piloted and adapted for use with nursing students, taking into consideration topics and methods suggested.

\section{ACKNOWLEDGEMENTS}

This paper is an outcome of the initial activity performed as part of the project entitled "Training modules for nursing students on gender and sexuality" that was possible through the award of the Health and Population Innovation Fellowship to the first author (2006-2008), supported by the Population Council, New Delhi.

\section{REFERENCES}

[1] Magnan, M.A., Reynolds, K.E. and Galvin, E.A. (2005) Barriers to addressing patient sexuality in nursing practice. Medsurg Nursing, 14, 282-289.

[2] Kelton, S. (1999) Sexuality education for youth with chronic conditions. Pediatric Nursing, 25, 491-495.

[3] Southard, N.Z. and Keller, J. (2009) The importance of assessing sexuality: A patient perspective. Clinical Journal of Oncology Nursing, 13, 213-217. doi:10.1188/09.CJON.213-217

[4] Redelman, M.J. (2008) Is there a place for sexuality in the holistic care of patients in the palliative care phase of life? American Journal of Hospice Palliative Care, 25, 366-368. doi:10.1177/1049909108318569

[5] Herson, L., Hart, K.A., Gordon, M.J. and Rintala, D.H. (1999) Identifying and overcoming barriers to providing sexuality information in the clinical setting. Rehabilitation Nursing, 24, 148-151.

[6] Vassiliadou, A., Stamatopoulou, E., Triantafyllou, G., et al. (2008) The role of nurses in sexual counselling of patients after myocardial infarction. Health Science Journal, 2, 111-118.

[7] Zeng, Y.C., Liu, X. and Loke, A.Y. (2011) Addressing sexuality issues of women with gynaecological cancer. Chinese nurses attitudes and practice. Journal of Advanced Nursing, 68, 280-282.

[8] WHO (1975) Education and training in human sexuality. The training of health professionals. Technical Report Series No. 572.

[9] Nusbaum, M.R., Gamble, G., Skinner, B. and Heiman, J. (2000) the high prevalence of sexual concerns among women seeking routine gynecological care. Journal of Family Practice, 49, 229-232.

[10] Handa, A. (1995) Sex education for adolescents. Nursing Journal of India, 38, 173-177.

[11] Indian Nursing Council (2001) Syllabus and regulations-Diploma in general nursing and midwifery. INC, New Delhi.

[12] Indian Nursing Council (2004) Syllabus-Basic B.Sc. INC, New Delhi.

[13] Washington, M. (2011) Critical analysis of undergraduate nursing programs to determine the need for sexuality and gender sensitization of student nurses. RGUHS Journal of Nursing Sciences, 1, 34-40.

[14] Chauduri, P. (2006) Sexual harassment in the workplaceExperiences of women in the health sector. Health and Population Innovation Fellowship Programme Working Paper, Population Council, New Delhi.

[15] Prasad, K. (2007) Sexual harassment in the workplace. The Nursing Journal of India, 98, 9-10.

[16] Andrews, W.C. (2000) Approaches to taking a sexual history. Journal of Women's Health and Gender-Based Medicine, 9, S21-24. doi:10.1089/152460900318821

[17] Washington, M. (2010). BEING-becoming empowered in nursing growth. Training guide for nursing students on sexuality and gender. Health and Population Innovation Fellowship Program, Population Council, New Delhi.

[18] Stokes, T. and Mears, J. (2000) Sexual Health and practice nurse: A survey of reported practice and attitudes. British Journal of Family Planning, 26, 89-96.

[19] Krishnaswamy, L. (2001) Psychosocial problems of adolescents-An exploratory study. Indian Journal of Continuing Nursing Education, 1, 34-38.

[20] Schuster, E.A., Unsain, I.C. and Goodwin, M.H. (1982) Nursing practice in human sexuality. Nursing Clinics of North America, 17, 345-349.

[21] Zalar, M.K. (1982) Role preparation of nurses in human sexual functioning. Nursing Clinics of North America, 17, 351-362.

[22] Waterhouse, J. (1993) Discussing sexual concerns with health care professionals: Positive attitudes in healthy subjects. Journal of Holistic Nursing, 11, 125-134. doi:10.1177/089801019301100202

[23] Waterhouse, J. and Matcalfe, M. (1991) Attitudes towards nurses discussing sexual concerns with patients. Journal of Advanced Nursing, 16, 1048-1054. doi:10.1111/j.1365-2648.1991.tb03365.x 